\title{
EFICÁCIA DA VACINA ANTI-RÁBICA ERA EM CAMUNDONGOS, FRENTE A QUATRO DIFERENTES VARIANTES ANTIGÊNICAS DO VÍRUS DA RAIVA*
}

\author{
Elcio Benedito Erbolato* \\ Egon Vieira da Silva ** \\ Omar Miguel \\ Pierre Sureau" \\ Pedro Manuel Leal Germano
}

\begin{abstract}
ERBOLATO. E.B. et al. Eficácia da vacina anti-rábica ERA em camundongos, frente a quatro diferentes variantes antigênicas do vírus da raiva. Rev. Saúde públ., S. Paulo, 23: 447-54, 1989.

RESUMO: Estudou-se a eficácia da vacina anti-rábica preparada em cultura primária de tecido renal de suínos, a partir da amostra ERA, na prevenção da raiva em camundongos, frente a quatro cepas antigenicamente distintas do vírus rábico, duas originadas de cão. C/SP e C/NG, uma originada de morcego, DR -19, e uma cepa fixa, CVS (Challenge Vırus Standard). O perfil antigênico desta cepa foi determinado pela técnica dos anticorpos anti-rábicos monoclonais antinucleocapside. Os animais foram vacinados, aos 21 dias de idade, por via intramuscular na face interna da coxa, com uma única dose de $0.05 \mathrm{ml}$ de vacina e desafiados aos 42 dias de idade, em conjunto com os animais do grupo testemunho. por via intramuscular na face interna da coxa, com $0,05 \mathrm{ml}$ da suspensão da cepa viral correspondente. Os resultados obtidos permitiram constatar que a vacina ERA protegeu $100 \%$ dos animais desafiados com as cepas C/SP, C/NG e DR.19 e $83 \%$ dos animais desafiados com a cepa CVS, enquanto que a mortalidade no grupo testemunho variou entre 70 e $90 \%$.
\end{abstract}

DESCRITORES: Vacina anti-rábica. Eficácia. Raiva, prevençåo.

\section{INTRODUÇÃO}

Na ausência de qualquer tipo de tratamento curativo contra a infeç̧ão rábica, o controle da doença repousa inteiramente sobre a imunoprofilaxia, como há cem anos quando Pasteur descobriu a possibilidade de vacinação (Atanasiu e Sureau ${ }^{5}$, 1987).

No que concerne à raiva animal, a vacinaçāo em massa dos suscetíveis constitui uma das principais medidas para o controle da doença (Kaplan e col. $\left.{ }^{20}, 1986\right)$. No mcio urbano a vacinação de cães e gatos rompe eficazmente a cadeia de trans- missão da raiva ao homem $\left(\right.$ Beran $\left.^{6}, 1985\right)$. Por outro lado a vacinação dos ruminantes, no meio rural diminui consideravelmente a ocorrência da raiva transmitida por quirópteros $\left(\mathrm{OMS}^{26}\right.$, 1984).

Dentre as vacinas anti-rábicas disponíveis na atualidade, as preparadas em culturas celulares são consideradas como as de melhor qualidade, pois apresentam elevado poder antigênico sendo, relativamente, desprovidas de proteínas estranhas, oferecendo, deste modo, maior grau de proteção e inocuidade (Precausta e col. ${ }^{27}, 1982$; Titoli e col. $\left.{ }^{37}, 1982\right)$. Dentre estas, destaca-se a

Síntese da Dissertação de Mestrado intitulada: "Contribuição ao estudo da imunoprofilaxia da raiva: eficácia da vacina anti-rábica "ERA" em camundongos, frente a quatro diferentes variantes antigénicas do vírus da raiva".

** Faculdade de Medicina Veterinária e Zootecnia da Universidade de São Paulo (aluno de pós-graduação).

*** Laboratório Regional de Apoio Animal (LARA), do Ministério da Agricultura - Rodovia Heitor Penteado, Km 3,5 13100 - Campinas, SP - Brasil.

Departamento de Prática de Saúde Pública da Faculdade de Saúde Pública da Universidade de São Paulo-Av. Dr. Arnaldo, 715 - 01255 - Sâo Paulo, SP - Brasil.

Unité de la Rage de L'Institut Pastcur de Paris - 28. Rue du Docteur Roux - 75724 - Paris - França. 
vacina ERA, originada a partir da cepa $S A D$, preparada em cultivo de células BHK e adaptada por Abelseth ${ }^{1}$ (1964) a cultura primária de tecido renal de suíno. A vacina ERA, na sua forma original, atenuada, é comprovadamente avirulenta para todas as espécies animais domésticas, quando aplicada por via intramuscular, desenvolvendo imunidade com duração de 2 a 3 anos, para caninos e bovinos, respectivamente (Abelseth $^{1,2,3}, 1964,1966,1975 ;$ Sikes $\left.^{30}, 1975\right)$. Assim, esta vacina, ao longo dos últimos anos, tem protegido eficazmente as diferentes espécies animais contra a raiva, não se registrando, principalmente, casos de acidentes vacinais (Abelseth ${ }^{3}, 1975$; Titoli e col. ${ }^{37}, 1982$ ).

A partir da utilização da técnica dos anticorpos anti-rábicos monoclonais foi possível identificar cepas distintas de virus, na Europa, na África, na Ásia e nas. Américas (Koprowski e Wiktor $^{23}$ 1980; Blancou e col. 8 1982; Charlton e col. 11, 1982; Sureau e Rollin '33, 1982; Sureau e col. $^{34,35}, 1982,1983$; Libeau e col. ${ }^{25}$, 1984; Webster e col. 38,1985 ; Smith e col. ${ }^{31}, 1986$; Germano e col. ${ }^{16,19}, 1988,1989$ ).

Apesar dos conhecimentos atuais sobre a ocorrência de diferentes cepas de vírus em uma mesma região, as vacinas anti-rábicas, utilizadas para o controle da infecção, continuam a ser preparadas a partir das cepas clássicas (OMS ${ }^{26}$, 1984). Portanto, assume relevante importância na prevenção da infecção rábica, năo só o conhecimento da existencia de diferentes cepas de vírus, mas, primordialmente, a eficácia das vacinas anti-rábicas utilizadas no campo, frente a essas mesmas cepas (Germano e col. ${ }^{17}, 1988$ ).

O objetivo do presente trabalho é apresentar o perfil antigenico do nucleocapside do CVS (Challenge Virus Standard) e avaliar a eficácia da vacina anti-rábica atenuada, preparada em cultura primária de tecido renal de suíno, a partir da amostra de vírus ERA, indicada para a prevenção da raiva nos ruminantes e nos carnívoros domésticos, frente a 4 cepas de vírus rábico, duas originadas de cão, uma de morcego e uma cepa fixa (CVS),utilizando camundongos como sistema biologico de suporte.

\section{MATERIAL E MÉTODO}

\section{Vírus}

Foram utilizadas 4 cepas de virus rábico, em suspensão a $20 \%$ em cérebros de camundongos, identificadas antigenicamente através da técnica dos anticorpos anti-rábicos monoclonais antinucleocapside, a saber:

- cepa C/SP isolada a partir de cão, procedente da cidade de Jales, São Paulo, terceira passagem em camundongos;

- cepa C/NG isolada a partir de cão, procedente da Nigéria, África, décima passagem em camundongos;

- cepa DR-19 adaptada às condições de laboratório, isolada a partir de morcego (Fuenzalida e Larghi ${ }^{15}, 1972$ ), e originária do Brasil, vigésima segunda passagem em camundongos;

- cepa CVS.

Os perfis antigênicos do nucleocapside das cepas C/SP, C/NG e DR-19 foram determinados por Germano e col. ${ }^{16}$ (1988), enquanto que o da cepa CVS é apresentado no presente trabalho.

\section{Vacina Anti-Rábica}

Foi utilizada a vacina anti-rábica preparada em cultura primária de tecido renal de suíno a partir da amostra de vírus rábico ERA atenuada, produzida no Laboratório Bio-Vet S.A, partida número 319/87.

\section{Animais}

Foram utilizados diferentes lotes de camundongos albinos suiços, fêmeas, nas seguintes etapas do trabalho:

\section{Determinação das diluições dos vírus}

Foram utilizados 240 animais, divididos em 4 grupos de igual tamanho. Os camundongos de cada grupo foram inoculados, aos 42 dias de idade, por via intramuscular com $0,05 \mathrm{ml}$ de suspensão viral, correspondente a cada uma das 4 cepas utilizadas para determinar o título capaz de matar, no máximo, $90 \%$ dos animais.

As diluiçōes obtidas foram da ordem de 1:10 para as cepas C/SP e C/NG, 1:60 para a cepa DR-19 e 1:80 para a cepa CVS. A diluição infectante de cada uma das cepas virais foi, posteriormente, inoculada nos camundongos dos diferentes grupos experimentais.

\section{Inoculação experimental}

Foram utilizados 200 animais com 21 dias de idade, pesando em média $11 \mathrm{~g}$, divididos em dois grupos experimentais: Grupo I formado por 80 camundongos não vacinados (testemunho), 
divididos em 4 subgrupos de 20 animais; Grupo II formado por 120 camundongos vacinados, também divididos em 4 subgrupos, estes com 30 animais cada.

O grupo dos camundongos vacinados recebeu uma única dose de $0,05 \mathrm{ml}$ da vacina em estudo aos 21 dias de idade, por via intramuscular, na face interna da coxa direita.

Todos os camundongos de ambos os grupos foram inoculados aos 42 dias de idade com 0,05 $\mathrm{ml}$ de suspensão viral, por via intramuscular, na face interna da coxa esquerda, obedecendo ao seguinte esquema:

Subgrupos 1 e 5 - animais inoculados com uma diluição 1:10 da cepa C/SP;

Subgrupos 2 e 6 - animais inoculados com uma diluição 1:10 da cepa C/NG;

Subgrupos 1 e 5 - animais inoculados com uma diluição 1:60 da cepa DR-19; e,

Subgrupos 2 e 6 - animais inoculados com uma diluição 1:80 da cepa CVS.

Após inoculação das suspensões virais, os camundongos de ambos os grupos experimentais foram mantidos em observação por um período de 30 dias. Dos animais que morreram durante esta fase, foram coletados os cérebros para pesquisa de partículas virais especificas, através da IFD.

\section{Titulaçáo das Cepas Virais}

As provas de inoculação intracerebral em camundongos e os respectivos cálculos das DL50 das diferentes cepas de vírus rábico utilizadas, foram realizadas segundo a técnica descrita por Koprowski $^{21}$ (1973).

Os títulos obtidos, expressos em DL50/0,03 ml, foram os seguintes: $10^{4.9}, 10^{4.5}, 10^{7.0}$ e $10^{7.7}$, respectivamente para as cepas $C / S P, C / N G, D R$ 19 e CVS.

\section{Titulaçáo da Vacina Anti-Rábica}

A vacina utilizada apresentou na prova de inoculaçăo intracerebral em camundongos (Koproswki ${ }^{21}$ 1973), um título da ordem de $10^{3,78} \mathrm{DL} 50 / 0,03 \mathrm{ml}$ e quando submetida a prova de protcção em cobaias (Koprowski ${ }^{22}, 1973$ ) forneceu resultado protetor igual a $100 \%$.

\section{Imunofluorescência direta}

A prova de IFD foi realizada de acordo com a técnica descrita por Dean e Abelseth ${ }^{13}$ (1973), utilizando-se microscópio binocular, marca Zeiss, com objetiva de imersão $40 \mathrm{X}$ provida de diafragma, ocular $10 \mathrm{X}$, campo escuro, com condensador cardióide, lâmpada HBO 200, filtro excitador VG1 e filtro barreira Zeiss 43.

O conjugado foi utilizado na diluiçăo $1: 80$ e a suspensão de CVS apresentou um título igual a $10^{7.3}$ DL50/0,03 ml.

\section{Anticorpos Monoclonais}

O perfil antigênico da cepa CVS foi determinado no laboratório do Centre Antirabique de l'Unité de la Rage do Instituto Pasteur de Paris.

A cepa viral foi analisada frente a uma bateria de 42 anticorpos anti-rábicos monoclonais anti-nucleocapside, utilizando a prova de imunofluorescência indireta (IFI) sobre decalques de cérebros de camundongos, de acordo com a técnica preconizada por Libeau e col. ${ }^{25}$ (1984).

\section{Análise estatística}

Aos resultados obtidos aplicou-se o teste de duas proporções, com aproximação normal (Berquó e col. 7 , 1980), para determinar se havia diferenças significantes entre as cepas rábicas, consideradas duas a duas, e os resultados obtidos entre as mortalidades de cada grupo experimental, para cada uma das cepas virais.

Adotou-se como nível de rejeição alfa igual a 0,05 e o valor crítico de " $Z$ " de alfa, 1,96.

\section{RESULTADOS}

A Tabela 1 apresenta o perfil antigênico do nucleocapside da cepa CVS determinado através da técnica dos anticorpos anti-rábicos monoclonais.

Os coeficientes de mortalidade do grupo de camundongos não vacinados (testemunho), determinados pelas diferentes cepas de vírus rábico, bem como os resultados de proteção, conferida pela vacina anti-rábica ERA, do grupo de animais vacinados e desafiados pelas 4 cepas em estudo, estão apresentados na Tabela 2.

A partir dos valores de mortalidade e proteção para ambos os grupos experimentais, expressos na Tabela 2, procedeu-se à análise estatística, utilizando-se o teste de duas proporções com aproximação normal, para determinar se havia diferenças significantes entre as cepas rábicas, consideradas duas a duas, originando-se a Tabela 3. 


\section{TABELA 1}

Resultados da determinação do perfil antigênico do nucleocapside da cepa CVS (Challenge Virus Standard) de vírus rábico, obtidós pela técnica dos anticorpos monoclonais, segundo os tipos de anticorpos testados. São Paulo, 1989.

\begin{tabular}{cc}
\hline Tipos de & Resultados \\
Anticorpos & \\
\hline
\end{tabular}

1. 502.2

2. 103.7

3. 206.3

4. 209.1

5. 229.1

6. 590.2

7. 515.3

8. 104.4

9. 111.2

10. 111.14

11. 239.10

12. 389.2

13. 377.7

14. 102.27

15. 222.9

16. 237.3

17. 120.2

18. 364.11

19. 714.3

20. 422.5

21. 816.1

22. 817.5

23. 818.5

24. 822.7

25. 701.9

26. 703.8

27. 715.3

28. 721.2

29. 801.1

30. 802.2

31. 803.6

32. 804.9

33. 805.3

34. 806.1

35. 807.5

36. 808.2

37. 187.5 .10

38. P41

39. PVB.1

40. 23.4

41. PVA. 3

42. 15.2

\footnotetext{
$+=$ Positivo

- = Negativo

I = Duvidoso
}

TABELA 2

Percentuais de mortalidade e proteção conferida pela vacina anti-rábica ERA em camundongos desafiados experimentalmente, por via intramuscular, com vírus da raiva, segundo os grupos experimentais e as cepas de vírus utilizadas no desafio. São Paulo, 1989.

\begin{tabular}{|c|c|c|c|c|c|c|c|}
\hline \multirow{3}{*}{ Cepas } & \multicolumn{7}{|c|}{ Camundongos } \\
\hline & \multicolumn{3}{|c|}{ Testemunhos } & \multicolumn{4}{|c|}{ Vacinados } \\
\hline & I & $\begin{array}{c}\mathrm{M} \\
\text { (F) }\end{array}$ & $\begin{array}{c}\text { Mort. } \\
(\%)\end{array}$ & (F) & $\begin{array}{c}M \\
(F)\end{array}$ & $\begin{array}{c}\text { Mort. } \\
(\%)\end{array}$ & $\begin{array}{l}\text { Prot. } \\
(\%)\end{array}$ \\
\hline $\begin{array}{l}\text { C/SP } \\
\text { C/NG } \\
\text { DR-19 } \\
\text { CVS }\end{array}$ & $\begin{array}{l}20 \\
20 \\
20 \\
20\end{array}$ & $\begin{array}{l}17 \\
14 \\
15 \\
18\end{array}$ & $\begin{array}{l}85,0 \\
70,0 \\
75,0 \\
90,0\end{array}$ & $\begin{array}{l}30 \\
30 \\
30 \\
30\end{array}$ & $\begin{array}{l}0 \\
0 \\
0 \\
5\end{array}$ & $\begin{array}{r}0,0 \\
0,0 \\
0,0 \\
17,0\end{array}$ & $\begin{array}{r}100,0 \\
100,0 \\
100,0 \\
83,0\end{array}$ \\
\hline $\begin{array}{ll}\mathrm{I} & = \\
\mathrm{M} & = \\
\text { Mort. } & =\end{array}$ & $\begin{array}{l}\text { Inoct } \\
\text { Mort } \\
\text { Mort }\end{array}$ & & & & $\begin{array}{l}\text { Pro } \\
\text { F }\end{array}$ & $\begin{array}{l}=\text { Prot } \\
=\text { Freq }\end{array}$ & $\begin{array}{l}\text { ção } \\
\text { iência }\end{array}$ \\
\hline
\end{tabular}

A Tabela 4 apresenta os valores da estatística "Z" e sua correspondente significância, em relação a comparação dos resultados obtidos en: tre as mortalidades de cada grupo experimental, segundo cada uma das cepas virais.

\section{DISCUSSÃO E CONCLUSÕES}

A cepa CVS, cujo perfil antigênico está apresentado na Tabela 1 , reagiu positivamente frente à quase totalidade dos anticorpos anti-rábicos monoclonais testados, exceção feita aos anticorpos 422.5 (reação negativa) e 187.5 .10 (reação duvidosa). O anticorpo 422.5 tem-se apresentado, sistematicamente, como negativo para todas as variantes antigênicas do vírus da raiva (Germano e col. ${ }^{16}, 1988$ ). Este tipo de reação tem sido observado independentemente da região geográfica e das espécies a partir das quais tenham sido isoladas essas variantes (Koprowski e Wiktor $^{23}$ 1980; Blancou e col. ${ }^{8}, 1982$; Charlton e col. $^{11}$, 1982; Schneider ${ }^{28}$, 1982; Sureau e col. ${ }^{34,35}$, 1982, 1983; Sureau e Rollin ${ }^{33}$ 1982). As cepas C/SP, C/NG e DR-19, também reagiram negativamente com este anticorpo (Germano e col. ${ }^{16}$, 1988).

A comparação do perfil antigénico da cepa CVS com os perfis das cepas C/SP, CNG e DR-19 determinados por Germano e col. ${ }^{16}$ (1988), evidenciou serem as quatro diferentes antigenicamente.

A análise da Tabela 2 permite evidenciar 
TABELA 3

Valores da estatística " $Z$ " e sua significância quando da utilização do teste de duas proporçỡes, para a comparação dos resultados obtidos entre as cepas de vírus rábico, duas a duas, segundo os grupos experimentais. São Paulo, 1989

\begin{tabular}{|c|c|c|c|c|c|c|}
\hline \multirow{3}{*}{ Cepas } & \multicolumn{6}{|c|}{ Camundongos } \\
\hline & \multicolumn{3}{|c|}{ Testemunhos } & \multicolumn{3}{|c|}{ Vacinados } \\
\hline & $\mathrm{C} / \mathrm{NG}$ & DR-19 & CVS & $\mathrm{C} / \mathrm{NG}$ & DR -19 & CVS \\
\hline $\begin{array}{l}\text { C/SP } \\
\text { C/NG } \\
\text { DR-19 }\end{array}$ & $1,13 \mathrm{NS}$ & $\begin{array}{l}0,79 \mathrm{NS} \\
0,35 \mathrm{NS}\end{array}$ & $\begin{array}{l}0,48 \mathrm{NS} \\
1,58 \mathrm{NS} \\
1,25 \mathrm{NS}\end{array}$ & $0,0 \mathrm{NS}$ & $\begin{array}{l}0,0 \mathrm{NS} \\
0,0 \mathrm{NS}\end{array}$ & $\begin{array}{l}2,33^{*} \\
2,33^{*} \\
2,33^{*}\end{array}$ \\
\hline
\end{tabular}

NS $=$ Não Significante

* $=$ Significante

\section{TABELA 4}

Valores da estatística " $Z$ " e sua significância, quando da utilização do teste de duas proporçôes, para a comparação dos resultados obtidos entre as mortalidades de cada grupo experimental, segundo as cepas de vírus rábico. São Paulo, 1989.

\begin{tabular}{llrl}
\hline \multirow{2}{*}{ Cepas } & \multicolumn{2}{c}{ Mortalidades } & " $\mathrm{Z}$ "' \\
\cline { 2 - 3 } & $\mathrm{T}(\%)$ & $\mathrm{V}(\%)$ & \\
\hline C/SP & 85,0 & 0,0 & $6,21^{*}$ \\
C/NG & 70,0 & 0,0 & $5,40^{*}$ \\
DR-19 & 75,0 & 0,0 & $5,66^{*}$ \\
CVS & 90,0 & 16,7 & $5,10^{*}$ \\
\hline
\end{tabular}

$\mathrm{T}=$ Testemunhos

$\mathrm{V}=$ Vacinados

* $=$ Significante

que no grupo constituído pclos camundongos não vacinados, testemunhos, o subgrupo inoculado com a cepa CVS foi o que apresentou coeficiente de mortalidade mais clevado (90\%); manteve, assim, inalterado o título, previạmente estabelecido para a suspensão viral de desafio. Em contrapartida, as demais cepas não foram capazes de reproduzir os mesmos resultados, quando aplicadas nas diluiçóes pré-determinadas, registrando-se coeficientes de mortalidade variáveis, de acordo com cada uma das cepas em estudo. Estes resultados podem ser considerados normais, pois tratam-se de cepas de vírus da raiva com características peculiares (Chantal e Blancou $\left.^{10}, 1985\right)$. Assim, a cepa CVS é mantida em condições de laboratório através de passagens contínuas em camundongos, resultando desta adaptação um grau de virulência muito elevado para esta espécie animal (Chantal e Blancou ${ }^{10}$, 1985). A cepa DR-19, por sua vez, é semi-adaptada às condições de laboratório, posicionando-se intermediariamente entre as cepas naturais e as fixas (Fuenzalida e Larghi $^{15}$, 1972; Larghi e $\left.\operatorname{Dias}^{24}, 1985\right)$, enquanto que as cepas C/SP e $\mathrm{C} / \mathrm{NG}$, ambas isoladas a partir de cães, são cepas naturais do vírus rábico (Germano e col. ${ }^{16}, 1988$ ). Com base nestes aspectos, a reprodutibilidade dos resultados pode ser afetada, principalmente em razão destas cepas não serem inteiramente adaptadas ao sistema biologico empregado.

Embora os valores percentuais das mortalidades, acarretados pelas diferentes cepas virais, tenham sido discrepantes, não se observaram diferenças significantes quando os resultados foram comparados através do teste duas proporções com aproximação normal, tal como pode ser constatado na Tabela 3. Com base neste tipo de análise, as 4 cepas mantiveram elevado grau de virulência, sendo capazes de matar entre $70 \%$ (C/NG) e $90 \%$ (CVS) da população de camundongos não vacinados a elas expostos.

Com relação ao grupo de camundongos vacinados, referido, também, na Tabela 2, observou-se que os subgrupos desafiados com as cepas C/SP, C/NG e DR-19 foram protegidos $100 \%$ com a vacina ERA. No que concerne ao subgrupo desafiado com a cepa CVS, só $83 \%$ da p. pulação foi protegida pela vacina. Estes resultadus, quando analisados estatisticamente, revelaram que houve diferença significante entre estes dois valores de proteção, conforme pode ser observado na Tabela 3. Contudo, de acordo com os criterios estabelecidos por Koprowski (1973) ${ }^{22}$ para os 
testes de potência de vacinas atenuadas, o nível de proteção conferido por uma vacina deste tipo deve ser de, no mínimo, $70 \%$ da população vacinada exposta ao vírus. Portanto, com base neste critério, a vacina ERA protegeu, eficazmente, os 4 subgrupos de camundongos contra as diferentes variantes antigênicas do vírus rábico. A diferença de magnitude observada, para o valor de proteção, para o caso específico da cepa CVS, pode ser, novamente, atribuído à clevada virulência desta cepa para camundongos (Chantal e Blancou ${ }^{10}$, 1985).

$\mathrm{Na}$ Tabela 4 constata-se que as diferenças de mortalidade nos subgrupos dos testemunhos e dos vacinados foram significantes estatisticamente para todas as cepas, inclusive a CVS, confirmando o elevado poder imunogênico da vacina ERA, frente às variantes antigênicas em estudo.

Em princípio, sempre se admitiu que as vacinas anti-rábicas, de uso corrente na prevenção da raiva são, em maior ou menor grau, eficazes contra quase todas as variantes antigênicas do vírus da raiva (Sikes e col. ${ }^{29}$, 1971; Blancou ${ }^{9}$, 1985). Acredita-se que as diferenças antigênicas, detectadas pela técnica dos anticorpos monoclonais, seriam as responsáveis pela variabilidade do poder patogênico, traduzido, principalmente, pela diversidade dos períodos de observação clínica de algumas cepas (Soulebot e col. ${ }^{32}$, 1982); Fekadu e Shaddock ${ }^{14}$, 1984; Germano e col. ${ }^{17,18}$, 1988), mas, por outro lado, haveria unicidade do poder imunogênico (Blancou', 1985; Larghi e $\left.\operatorname{Diaz}^{24}, 1985\right)$.

No caso particular da vacina anti-rábica ERA, os trabalhos de Abelseth ${ }^{1,2}(1964,1966)$ demonstraram que todas as especies animais vacinadas e desafiadas com cepas originadas de raposas foram eficazmente protegidas contra a raiva. A partir destes resultados, este tipo de vacina passou a ser empregado, na prática de campo, para a prevenção da infecção rábica de todos os animais domésticos, sobretudo dos bovinos (Arnold e col. ${ }^{4}, 1973$ ) e dos caninos (Sikes $\left.{ }^{30}, 1975\right)$.

Ao longo dos últimos anos, porem, a indicação da vacina ERA tem sido mantida, tão so- mente, para os ruminantes e para os carnívoros domésticos, e dentre estes quase que exclusivamente para os cães (Blancou', 1985; Chantal e Blancou $\left.^{10}, 1985\right)$. Este tipo de recomendação prende-se, fundamentalmente, ao receio que os pesquisadores e autoridades em saúde manifestam em relação à possibilidade das vacinas antirábicas vivas poderem causar acidentes pós-vacinais provocando a raiva $\left(\mathrm{OMS}^{26}, 1984\right)$, e também, devido ao surgimento de vacinas inativadas de elevado poder imunogênico e livres desses tipos de riscos (Precausta e col. ${ }^{27}$, 1982; Wunner e col. $^{39}$, 1983; OMS $^{26}$ 1984; Chantal e Blancou ${ }^{10}$, 1985; Chomel e col. ${ }^{12}$, 1985; Atanasiu e Sureau ${ }^{5}$, 1987).

Considerando-se a importância da vacinação dos animais domésticos, como medida preventiva das mais relevantes para o controle da raiva urbana e rural (Tierkel $^{36}$, 1975; Beran ${ }^{6}$, 1985; Chomel e col. ${ }^{12}$, 1985; Kaplan e col. ${ }^{20}$, 1986), aliada à existência de inúmeras variantes antigénicas do vírus da raiva na natureza (Charlton e col. ${ }^{11}$, 1982; Sureau e col. ${ }^{34,35}$ 1982, 1983; Webster e col. ${ }_{5}^{38}$, 1985; Smith e col. ${ }^{31}$, 1986; Atanasiu e Sureau ${ }^{5}, 1987$; Germano e col. ${ }^{19}, 1989$ ), impõe-se a necessidade de adotar-se, na profilaxia da infecção, uma vacina anti-rábica que possa proteger, eficazmente, os suscetíveis contra qualquer cepa rábica, conferindo-lhes um período de imunização prolongado $\left(\mathrm{OMS}^{26}, 1984\right)$.

Assim, com base nos resultados obtidos no presente trabalho, somados às observações realizadas no campo, pode-se concluir que a vacina ERA preenche os quesitos mínimos necessários para a prevenção da raiva nos ruminantes domésticos e nos cães, sobretudo por sua capacidade em proteger os suscetíveis contra diferentes variantes antigênicas do vírus rábico. Contudo, dada a diversidade de cepas rábicas existentes no país (Germano e col. ${ }^{19}, 1989$ ), faz-se necessária continuidade de estudos similares, no sentido de verificar se a vacina anti-rábica ERA continua mantendo este comportamento frente a outros tipos de variantes antigéniças do virus da raiva. 
ERBOLATO, E.B. et al. [Evaluation of ERA anti-rabies vaccine against four different antigenic strains of rabies virus in mice]. Rev. Saúde públ, S. Paulo, 23: 447-54, 1989.

ABSTRACT: ERA anti-rabies vaccine prepared in kidney tissue culture was evaluated against four different antigenic strains of rabies virus in mice: two of them dog strains, CSP and CNG, another a bat vampire strain, DR-19, and the CVS strain. The CVS antigenical characteristics were determined by means the antinucleocapsid monoclonal antibodies technique. Twenty one days old mice were vaccinated, intramuscularly, in the inner side of the thigh, with $0.05 \mathrm{ml}$ of vaccine and challenged at 42 days old, together with thase of the control group, intramuscularly, in the inner side of the thigh, with $0.05 \mathrm{ml}$ of the corresponding viral strain dilution. The ERA anti-rabies vaccine protected $100 \%$ of all the mice challenged with C/SP, CNNG and DR-19 strains and $83 \%$ of those challenged with CVS. The control groups mortality rate varied between 70 and $90 \%$.

KEYWORDS: Rabies vaccine. Efficacy. Rabies, preventive and control.

\section{REFERÊNCIAS BIBLIOGRÁFICAS}

1. ABELSETH, M.K. An attenuated rabies vaccine for domestic animals produced in tissue culture. Can vet $J$., 5:279.86, 1964.

2. ABELSETH, M.K. The growth of rabies virus in tissue culture and its use as a living attenuated vaccine for domestic animals. St. Paul, Minn., 1966 [Ph.D. Thesis University of Minnesota].

3. ABELSETH, M.K. Bovine vaccines - past and present. In: Baer, G.M., ed. The natural histony of rabies. New York, Academic Press, 1975. v.2, p. 203-19.

4. ARNOLD, R.M.; PERITZ, F.J.; SUREAU, P.; STOURAITIS, P.; VARGAS, V. Immunity against paralytic rabies in cattle following vaccination with ERA vaccine under ranch conditions in Bolivia. Part II Duration of immunity. Trop. anim. Hlth Prod, 5:1-5, 1973.

5. ATANASIU, P. \& SUREAU, P. Rage In: Encyclopedie Medico Chirurgicale Paris, 1987. Maladies Infectieuses, $8065 \mathrm{C} 10$.

6. BERAN, G.W. Prophylaxie sanitaire de la rage des chiens et des chats. In: Pasteur et la rage. Paris, Ministére de l'Agriculture, 1985. p. 215-S-220-S. (Informations Techniques des Services Vétérinaires, 92-95).

7. BERQUO, E. Bioestatística São Paulo, E.P.U., 1980.

8. BLANCOU, J.; ANDRAL, L.; MANNEN, K. Variantes antigeniques du virus rabique en France. Etude par anticorps monoclonaux. Comp. Immunol. Microbiol. infect Dis., 5:95-9, 1982.

9. BLANCOU, J. La vaccination antirabique des animaux domestiques. Ann. Inst. Pasteur/Virol., 136E:475-82, 1985.

10. CHANTAL, J. \& BLANCOU, J. Le virus rabique. In: Pasteur et la rage. Paris, Ministère de l'Agriculture, 1985. p. 281-92. (Informations Techniques des Services Vétérinaires, 92-95).

11. CHARLTON, K.M.; CASEY, G.A; BOUCHER, D.W.; WIKTOR, TJ. Antigenic variants of rabies virus. Comp. Immunol Microbiol infect. Dis., 5:113-5, 1982.

12. CHOMEL, B.; CHOMEL, R.; SAINT-GERAND, A.L. Prophylaxie de la rage animale. In: Reunion Franco-Colombienne, Bogotá, 1984. Deux zoonoses majeures: la rage et la brucellose Lyon, Bosc Frères, 1985. p. 29-48. (Collection Fondation Marcel Merieux).
13. DEAN, D.J. \& ABELSETH, M.K. The fluorescent antibody test. In: World Health Organization. Laboratory techniques in rabies. 3rd ed. Geneva, 1973. p. 73-84.

14. FEKADU, M. \& SHADDOCK, J.H. Peripheral distribution of virus in dogs inoculated with two strains of rabies virus. Amer. J. vet Res, 45:724-9, 1984.

15. FUENZALIDA, E. \& LARGHI, O.P. Caracteristicas de una cepa de virus rábico aislada del cerebro de Desmodus rotundus. BoL Ofic. sanit panamer., 73:93-8, 1972.

16. GERMANO, P.M.L.; SILVA, E.V.; SUREAU, P. Determinaçâo do perfil antigenico de 3 cepas de virus rábico, isoladas no Brasil, através da técnica dos anticorpos monoclonais antinucleocapside. Rev. Fac. Med vet. Zootec. Univ. S. Paulo., 25:199-295, 1988.

17. GERMANO, P.M.L.; MIGUEL, O.; ISHIZUKA, M.M.; SILV.A, E.V. Avaliação de três cepas de virus rábico, antigenicamente distintas, em camundongos. I - Estudo dos períodos de observação clínica. Rev. Saúde púbL, S. Paulo, 22:375-83, 1988.

18. GERMANO, P.M.L.; MIGUEL, O.; ISHIZUKA, M.M.; SILVA E.V. Avaliação de tres cepas de virus rábico, antigenicamente distintas, em camundongos. II - Estudo da disseminação viral por diferentes órgãos. Rev. Saíde públ, S.Paulo, 22:473-8, 1988.

19. GERMANO; P.M.L.; SILVA, E.V.; SILVA, E.V;; MIGUEL, O.; SUREAU, P. Variantes antigenicas del virus rabico aisladas en el Nordeste y Sudeste de Brasil. BoL Ofic. sanit panamer:, 1989. [No prelo].

20. KAPLAN, C.; TURNER, G.S.; WARREL, D.A. Rabies, the facts. 2nd ed. Oxford, Oxford University Press, 1986.

21. KOPROWSKI, $\mathrm{H}$. The mouse inoculation test. In: World Health Organization. Laboratory techniques in rabies. 3rd ed. Geneva, 1973. p. 85-93.

22. KOPROWSKI, H. Guineapig potency test for chicken-embryo vaccine. In: World Health Organization. Laboratory techniques in rabies. 3rd ed. Geneva, 1973. p. 287.91.

23. KOPROWSKI, H. \& WIKTOR, T.J. Monoclonal antibodies against rabies virus. In: Kennet, R.H.; McKearn, T.J.; Bechtol, K.B., eds. Monoclonal antibodies-hybridomas: a new dimension in biological analysec New York, Plenum Press, 1980. p. 335-51. 
24. LARGHI, O.P. \& DIAZ, A.M.D. Cross protection of mice against different rabies virus isolates. $\mathrm{Zbl}$. bakt., 259:268-74, 1985.

25. LIBEAU, G.; LAFON, M.; ROLLIN, P.E. Etude de la spécificité d'anticorps monoclonaux obtenus avec la souche devirus de.rage Pasteur PV.Rev. Elev., 37:383-94, 1984.

26. ORGANIZATION MONDIALE DE LA SANTE. Comite d'Experts de la Rage, $7^{\circ}$ Geneve, 1983. Rapport. Genève, 1984. (Sérię de Rapports Techniques, 709)

27. PRECAUSTA, P.; SOULEBOT, J.P.; BUGAND, M; BRUN, A; CHAPPUIS, G. Modalités de production et immunite conferee par un vaccin antirabique inactive provenant de culture cellulaire. Comp. Immunol. Microbiol infect. Dis., 5:217-26, 1982.

28. SCHNEIDER, L.G. Antigenic variants of rabies virus. Comp. Immunol Microbiol infect Dis., 5:101-7, 1982.

29. SIKES, R.K.; CLEARY, W.F.; KOPROWSKI, H.; WIKTOR, T.J.; KAPLAN, M.M. Effective protection of monkeys against death from street virus by postexposure administration of tissue culture rabies vaccine. Bull. h/d Hlih Org., 45:1-11, 1971.

30. SIKES, R.K Canine and feline vaccines - past and present. In: Baer, G:M., ed. The natural history of rabies. New York, Academic Press, 1975. v. 1, p. 273-301.

31. SMITH, J.S.; REID-SANDEN, F.L.; ROUMILLAT, L.F.; TRIMARCHI, C.; CLARK, K.; BAER, G.M.; WINKLER, W.G. Demonstration of antigenic variation among rabies virus isolates by using monoclonal antibodies to nucleocapsid proteins. J. clin. Microbiol, 24:573-80, 1986.

32. SOULEBOT, J.-P.; BRUN, A.; CHAPPUIS, G.; GUILLEMIN, F.; TIXIER, G. Rabies virus pathogenicity and challenge: infuence of the method of preparation, the route of inoculation, and the species. Comparison of the characteristics of the modified fixed and wild strains. Comp. Immunol Microbial infect Dis., $5: 71-8,1982$.

33. SUREAU, P. \& ROLLIN, P.E. Variantes antigeniques du virus rabique; souches des rues de France, d'Afrique, de Madagascar et d'Asie: resultats préliminaires obtenus avec des anticorps monoclonaux antinuclécapside. Comp. Immunol Microbiol infect. Dis., 5:109-12, 1982.

34. SUREAU, P.; ROLLIN, P.E.; CHADL, A; ZELLER, H. Etude a l'aide d'anticorps monoclonaux des caractéristiques antigeniques de souches de virus rabiques de Tunisie. Arch Inst. Pasteur Tunis., 59:89-97, 1982.

35. SUREAU, P.; ROLLIN, P.E.; WIKTOR, T.J. Epidemiologic analysis of antigenic variations of street rabies virus: detection by monoclonal antibodies. Amer. J. Epidem, 117:605-9, 1983.

36. TIERKEL, E.S. Control of urban rabies. In: Baer, G.M., ed. The natural history of rabies. New York, Academic Press, 1975.v. 2, p. 189-201.

37. TITOLI, F.; PESTALOZZA, S.; IRSARA, A.; PALLIOLA, E.; FRESCURA, T.; CIVARDI, A. Recherche sur le virus atténué de la rage, souche ERA, chez de bovins et des chiens vaccines avec des doses multiples. Comp. Immunol. Microbiol. infect. Dis., S:193-7, 1982.

38. WEBSTER, W.A; CASEY G.A; CHARLTON, KM.; WIKTOR, T.J. Antigenic variants of rabies virus in isolates from Eastern, Central and Northern Canada. Canad. J. comp. Med, 49:186-8, 1985.

39. WUNNER, W.H.; DIETZSCHOLD, B.; CURTY, P.J.; WIKTOR, T.J. Rabies subunit vaccines. J. gen. Virol, 64:1649-56, 1983.

Recebido para publicação em 2/6/1989 Reapresentado em 22/9/1989 Aprovado para publicação em 26/9/1989 